\title{
Escolha de áreas prioritárias de conservação de anfíbios anuros do Cerrado através de um modelo de populações centrais-periféricas
}

\author{
Gabriela C. C. Padua ${ }^{1}$, Miriam P. Pinto² \& José A. F. Diniz-Filho ${ }^{1,2}$
}

1. Departamento de Biologia, Universidade Católica de Goiás, Goiânia, Goiás. (gabrielaccp@yahoo.com.br)

2. Departamento de Biologia, ICB, Universidade Federal de Goiás, Caixa Postal 131, 74001-970 Goiânia, Goiás.

\begin{abstract}
Reserve selection for anurans in the Cerrado using a central-periphery population model. Habitat loss causes great threats to biological diversity, and one of the alternatives to protect biodiversity is reserve planning using optimization tools to establish conservation priority areas. In this study, a simulated annealing algorithm was used to analyze the influence of species distribution margins on selection of areas in Cerrado, for 131 anurans species. For this purpose, we used two databases: one containing the original species distribution, and another with the periphery of distributions excluded. Networks selected using the original distributions contained 17 cells, whereas networks found with the reduced distributions were larger, with 22 cells. The irreplaceable cells were the same in all networks, and new regions of replaceable cells in the margins of the biome arise when distributions without peripheral areas were considered.
\end{abstract}

KEYWORDS. Complementarity, reserve selection, amphibians, central-peripheral populations, simulated annealing.

RESUMO. Uma das maiores ameaças à diversidade biológica é a perda de hábitat, de modo que uma das alternativas para proteção da biodiversidade é a seleção de reservas pela utilização de procedimentos de otimização para estabelecer áreas prioritárias para conservação. Neste estudo, um algoritmo simulated annealing foi usado para verificar como a periferia das distribuições das espécies influencia na seleção de áreas no Cerrado para conservação de 131 espécies de anfíbios anuros. Dois conjuntos de dados foram analisados, um contendo a distribuição original das espécies e outro excluindo a periferia das distribuições. As redes ótimas encontradas a partir das distribuições originais contiveram 17 quadrículas enquanto aquelas encontradas a partir das distribuições restritas foram maiores, com 22 células. As células com alto grau de insubstituibilidade foram mantidas em todas as redes e novas regiões de células substituíveis, localizadas na margem do bioma, surgiram quando apenas as distribuições reduzidas foram usadas.

PALAVRAS-CHAVE. Complementaridade, seleção de reservas, anfíbios, populações centrais-periféricas, simulated annealing.

A diversidade global está mudando rapidamente como uma resposta complexa às diversas mudanças ambientais causadas pelo homem (VIтоUSEK et al., 1997). Globalmente, ecossistemas intactos estão sendo degradados a uma taxa média de $1,2 \%$ ao ano, sendo que a maior ameaça à diversidade biológica é a perda de hábitats (PRIMACK \& RODRIGUES, 2001; BALMFORD et al., 2002). Um meio de identificar áreas prioritárias para conservação é através de hotspots, cuja análise baseiase em dois critérios: endemismo e grau de ameaça pela degradação de hábitats naturais (MYERs et al., 2000). Nenhum dos 25 hotspots identificados por MYers et al., (2000) mantém atualmente mais que um terço de sua área original, sendo que, historicamente, cobriam $12 \%$ de toda a superfície terrestre (BrooKs et al., 2002). O Cerrado brasileiro, assim como a Mata Atlântica, é um destes hotspots (MYERs et al., 2000).

O Cerrado vem sofrendo com altas taxas de perda de biodiversidade pela ocupação humana e expansão da agricultura (KLINK \& MoREIRA, 2002). Por isso, estratégias de conservação urgentes são importantes para esse bioma. O declínio de populações de anfíbios, principlamente na Austrália, América Central e nordeste do Pacífico dos Estados Unidos, tem sido foco de pesquisas nos últimos 12 anos (LANOo, 2005). As causas do declínio das populações de anfíbios, tanto de populações localizadas dentro de áreas protegidas quanto fora dessas áreas ainda são incertas, mas existe um consenso de que quatro fatores principais estão envolvidos: mudança climática, poluição, aumento da radiação de raios ultravioleta $\mathrm{B}$ (UVB) e doenças infecciosas (LANOO, 2005). A maioria dos dados sobre declínio populacional de anfíbios é da América do Sul (Equador e Brasil), mas nos trópicos as espécies de anfíbios são monitoradas insuficientemente (STUART et al., 2004). Esses fatos combinados tornam o grupo carente por ações rápidas para estratégias de conservação.

Atualmente, métodos sofisticados de seleção de áreas com ferramentas computacionais estão sendo desenvolvidos para ajudar na identificação de áreas que maximizem a representação da diversidade regional (CABeza \& Mollanen, 2001). Normalmente, esses procedimentos de seleção de áreas prioritárias são estabelecidos com base no conceito de complementaridade (Margules et al., 1988; Pressey et al., 1997). Complementaridade é uma medida do quanto uma área contribui para a representação de espécies não representadas previamente, sendo dependente da composição de qualquer área previamente selecionada (PRESSEY et al., 1993). Os algoritmos baseados em complementaridade procuram por áreas onde todas as espécies de interesse estão representadas na menor área possível (GASTON et al., 2001). Uma alternativa ao uso de algoritmos de seleção de reservas baseada em complementaridade foi proposta por PRESSEY et al. (1994), através do mapeamento de um atributo contínuo chamado insubstituibilidade (FERRIER et al., 2000). É uma medida da importância de uma área com relação ao objetivo de 
proteger todas as espécies. Áreas totalmente "insubstituíveis" contêm espécies não encontradas em nenhum outro lugar. O valor de insubstituibilidade pode ser usado para verificar o padrão espacial das opções de áreas numa região e possível substituição de qualquer área, dadas as restrições na alocação de reservas (FERRIER et al., 2000).

Alguns trabalhos sugerem que os algoritmos de seleção de reservas pelo método de complementaridade podem selecionar preferencialmente populações que estejam nas margens das distribuições das espécies (Araújo \& Williams, 1999; Gaston et al., 2001). Isso resulta na seleção de áreas com alta riqueza de espécies, pela grande sobreposição nas margens de suas distribuições. Porém, as populações escolhidas de cada espécie podem ter uma probabilidade relativamente baixa de persistência, já que populações periféricas encontramse em baixa densidade (VucETich \& WAite, 2003) como resultado de stress ambiental e/ou genético (KLUTH \& BRUElHEIDE, 2005). Assim, populações periféricas são mais propensas a sofrer com as ameaças do que as populações mais centrais, aumentando o risco de extinção daquelas (ARAúJo \& WiLliAMS, 1999). Este fato poderia comprometer um dos quesitos principais da conservação da biodiversidade, a persistência das espécies. O objetivo deste trabalho foi verificar como a periferia das distribuições das espécies influencia na seleção de áreas para conservação de anuros no Cerrado. Algoritmos de seleção baseados no conceito de complementaridade foram usados para selecionar sistemas de reservas de duas maneiras: contendo a distribuição original das espécies de anuros (centro e periferia) ou apenas as áreas centrais das distribuições (ou seja, eliminando as áreas periféricas da distribuição).

\section{MATERIAL E MÉTODOS}

As extensões de ocorrência (GASTON \& BLACKBURN, 2000) de 131 espécies de anfíbios anuros do Cerrado brasileiro foram mapeadas sobre uma grade sobreposta a este bioma (Fig. 1) contendo 181 células com resolução espacial de $1^{\circ}$ de latitude e $1^{\circ}$ de longitude (Diniz-FILHO et al., 2004, 2007).

Duas matrizes de incidência (presença ou ausência) com 181 linhas (células) e 131 colunas (espécies) cada foram elaboradas de acordo com a sobreposição das extensões de ocorrência das espécies ao longo das células. A primeira matriz foi estabelecida a partir da distribuição geográfica completa das espécies e a segunda, com distribuições limitadas, excluindo-se as bordas da distribuição de cada espécie. Ao longo do limite de distribuição de cada espécie, uma região periférica com a largura de uma célula foi retirada das bordas para um total de 60 espécies com menos de 100 células de ocorrência (e. g., Fig. 2). Para as 27 espécies com mais de 100 células de ocorrência dentro do Cerrado, duas células foram retiradas ao longo da região periférica. Em alguns casos a distribuição da espécie foi tão restrita que a exclusão da área periférica leva à exclusão da espécie (44 espécies com distribuições menor que 20 células). Nestes casos, a extensão da ocorrência original foi mantida. Algumas espécies estão presentes em outros biomas além do Cerrado, e nestes casos as áreas de distribuição que extrapolavam a grade do Cerrado não foram alteradas (e. g., Fig. 2), mas isso não afeta as análises realizadas. A partir de cada matriz, original e com distribuições limitadas, foram obtidos os valores de riqueza de cada quadrícula.

$\mathrm{O}$ algoritmo simulated annealing [através do módulo SSM - Site Selection Module, do programa SITES, (ANDELMAN et al., 1999) com um milhão de iterações] foi aplicado a esses dois conjuntos de dados. Este algoritmo foi rodado 100 vezes e a seguinte função de custo foi calculada para cada solução:

Custo Total $=\sum$ Custo sítio ou célula $i+\sum \mathrm{Pj}$,

onde $P j$ é a penalidade pela não representação de cada espécie $j$ (variando de 1 a 131 espécies) e $i$ é cada célula (variando de 1 a 181 células). Foi atribuída

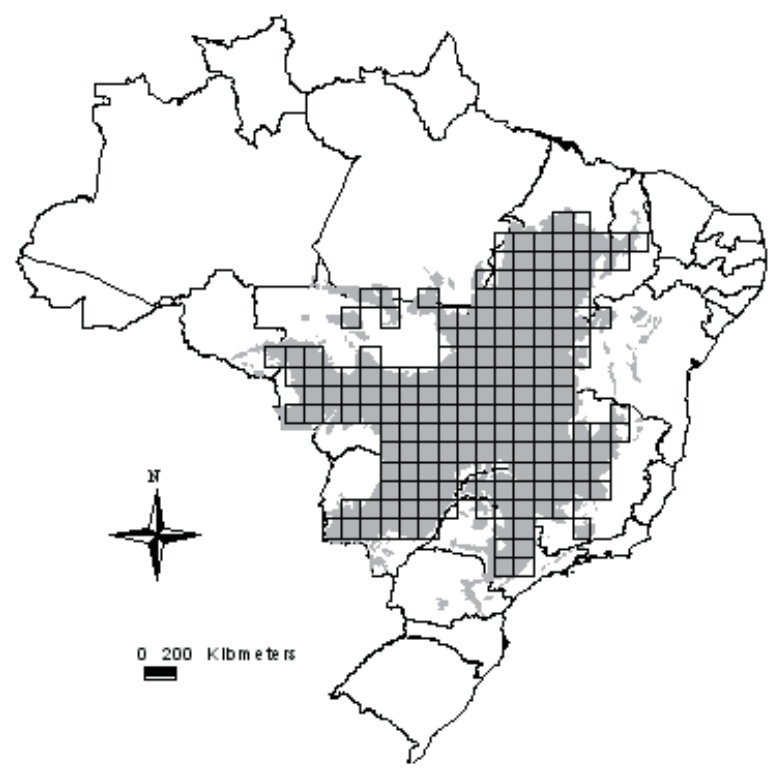

Fig. 1. Grade definida sobre o bioma Cerrado do Brasil.

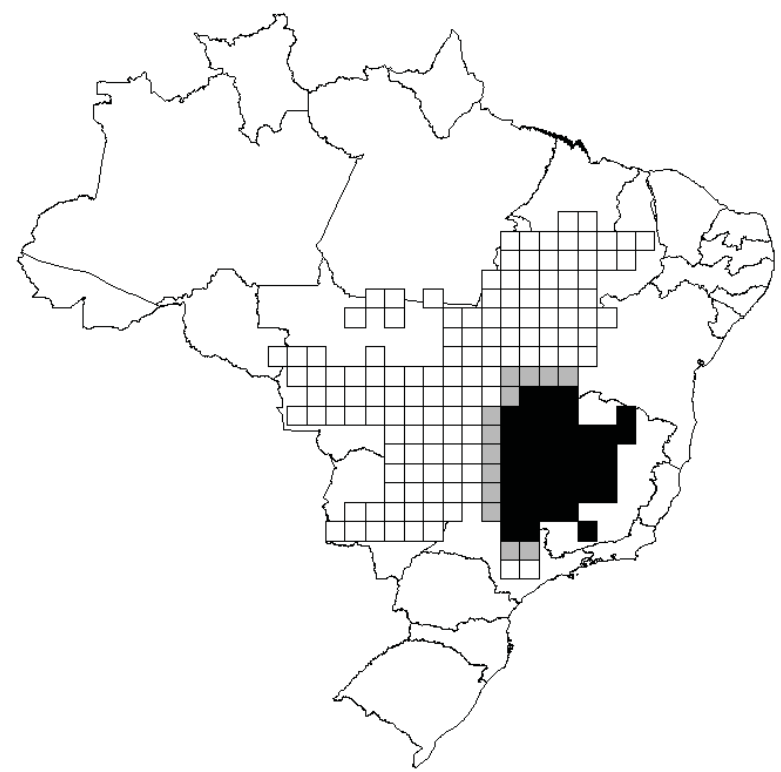

Fig. 2. Exemplo de exclusão da borda da distribuição de Hyla tritaenita. Distribuição original (cinza e preto). Limite de distribuição a oeste da região periférica com uma célula retirada da borda. A sudeste do bioma a distribuição da espécie continua além do bioma estudado, então a distribuição é mantida sem retirada da borda. 
penalidade 2 para a perda de cada espécie e custo 1 para a inclusão de cada célula na rede a fim de tentar garantir que todas as espécies fossem representadas na maioria das soluções. As soluções com menores custos e com todas as espécies representadas foram usadas como resultados. A partir desses resultados foram gerados dois mapas de insubstituibilidade das células. $\mathrm{O}$ valor da insubstituibilidade é a freqüência de cada célula nas soluções (métodos mais complexos para estimar a insubstituibilidade podem ser encontrados em FERRIER et al., 2000), tal valor varia de 1 (célula presente em 100\% das soluções) e 0 (célula não utilizada para solução). Os dois mapas foram então comparados utilizando um teste t-pareado, comparando-se as insubstituibilidades ao longo das 181 células.

\section{RESULTADOS E DISCUSSÃO}

Os mapas do padrão espacial de riqueza obtidos a partir das distribuições originais e das distribuições sem as bordas para as 131 espécies de anfíbios anuros no Cerrado estão representados nas Figuras 3 e 4, respectivamente. Existe um padrão claro de aumento no número de espécies em direção à região sudeste do bioma em ambos os conjuntos de dados, sendo que as células mais ricas se tornam mais concentradas e restritas a esta região quando as bordas das distribuições são retiradas.

As áreas ótimas encontradas a partir do conjunto de dados originais incluindo a distribuição completa de todas as espécies analisadas contêm 17 células. Dentre as 100 soluções obtidas, 97 representavam todas as espécies com o mínimo de células possível e apenas estas foram usadas na construção do mapa do padrão espacial de insubstituibilidade (Fig. 5). Foram obtidas várias células com alto grau de insubstituibilidade e estas geralmente ocorreram mais isoladamente do que grandes agrupamentos de células mais substituíveis, como aquele da região nordeste do bioma. Este grande agrupamento

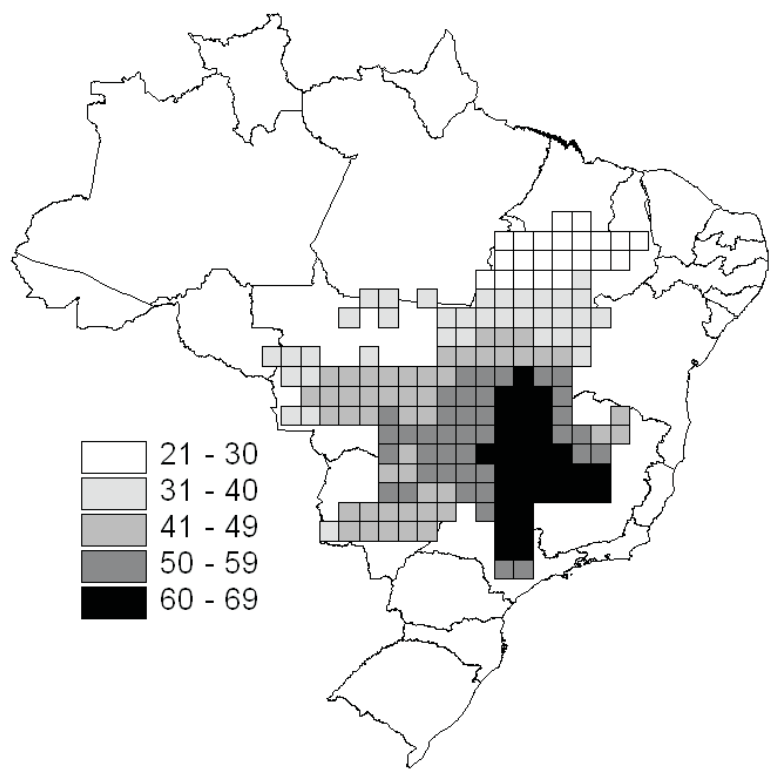

Fig. 3. Mapa do padrão espacial de riqueza obtido a partir das distribuições originais das 131 espécies de anfíbios anuros no Cerrado. de células que podem ser substituídas umas pelas outras provavelmente está relacionado com o turnover de espécies, ou seja, com o padrão espacial de diversidade beta de anfíbios anuros nesta região (BINI et al., 2004). As células com grau de insubstituibilidade entre 45 e 52 (em um total de 97) estão também agrupadas, refletindo a mesma composição de espécies existentes nessas células. Parte das células altamente insubstituíveis coincide com a região de maior riqueza do Cerrado, localizada a centroleste e sudeste, e o restante das células muito insubstituíveis está em regiões de transição do Cerrado com o Pantanal.

Usando o conjunto de dados construído excluindose as células da borda das distribuições das espécies, as 100 soluções encontradas representavam as 131 espécies de anuros com o mínimo de células possível (22 células) uma rede maior que aquela obtida analisando-se as distribuições originais. Todas as soluções foram usadas na construção do mapa de insubstituibilidade (Fig. 6). As células com alto grau de insubstituibilidade têm a mesma localização (antes e depois da retirada das bordas), pois estas são determinadas pelas espécies de distribuição restrita que fazem com que estas células estejam sempre presentes nas diversas soluções (TsuJI \& TsUBAKI, 2005). A retirada da periferia das distribuições, priorizando assim a região central, teve forte influência sobre o número de células selecionadas, que aumentou quando os dados sem as bordas foram utilizados para gerar as redes. Isso alterou também a configuração espacial dos agrupamentos de células com baixo grau de insubstituibilidade, como aqueles novos valores nas regiões leste e sudoeste (Fig. 6). A Figura 7 confirma o aumento geral do grau de insubstituibilidade nas células do bioma quando as redes foram selecionadas usando as distribuições limitadas das espécies $(\mathrm{t}=2,85 ; \mathrm{P}<0,05)$.

Como sugerido por SMith et al. (2001), existem várias razões da importância das zonas de transição para a persistência em longo prazo da biodiversidade. Porém,

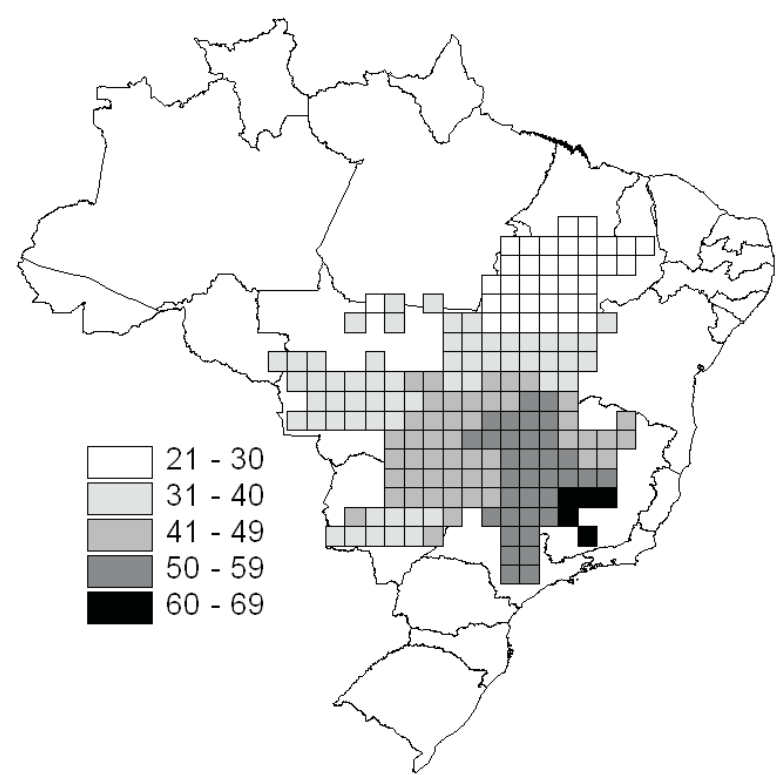

Fig. 4. Mapa do padrão espacial de riqueza obtido a partir das distribuições sem as bordas para as 131 espécies de anfíbios anuros no Cerrado. 


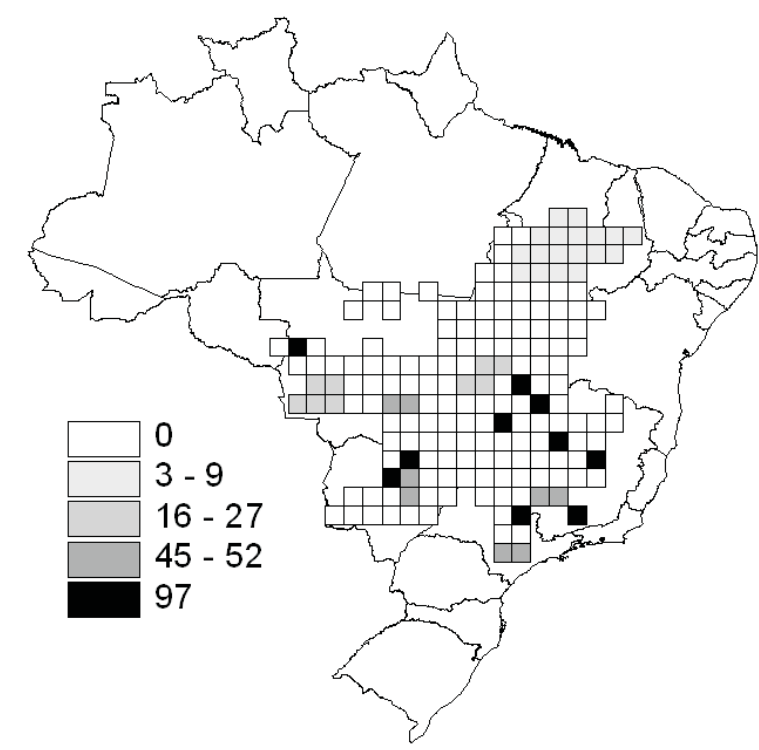

Fig. 5. Padrões espaciais de insubstituibilidade das células obtidos a partir de 97 soluções utilizando-se as distribuições originais das espécies de anuros no Cerrado.

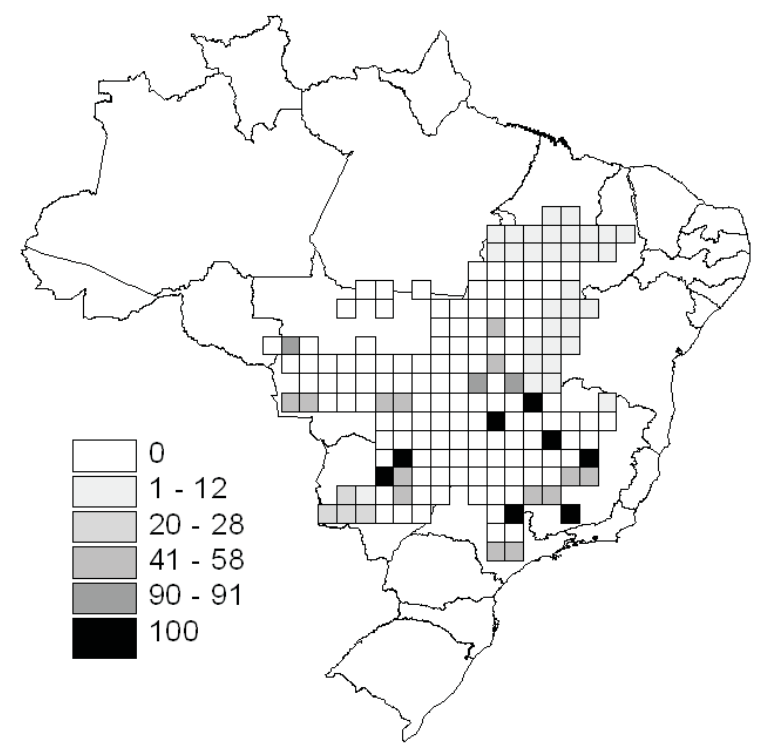

Fig. 6. Padrões espaciais de insubstituibilidade das células obtidos a partir de 100 soluções utilizando-se as distribuições das espécies de anuros no Cerrado sem as periferias.

também populações abundantes e menos variadas no centro das distribuições das espécies têm um papel fundamental na manutenção de populações viáveis (LAwTon, 1993), sendo uma escolha mais segura para conservação. Idealmente, a representação de cada espécie na margem e na periferia de sua distribuição seria mais eficiente, mas recursos para conservação são escassos e não deve ser possível conservar toda distribuição de cada espécie (ARAúJo, 2002). O aumento da importância dada a conservação e representação de uma espécie provavelmente implicaria na redução da representação de outras, concentrando os esforços em poucas espécies, o que pode não ser desejável. Assim, estratégias para aumentar a persistência global das espécies selecionando populações mais viáveis de cada

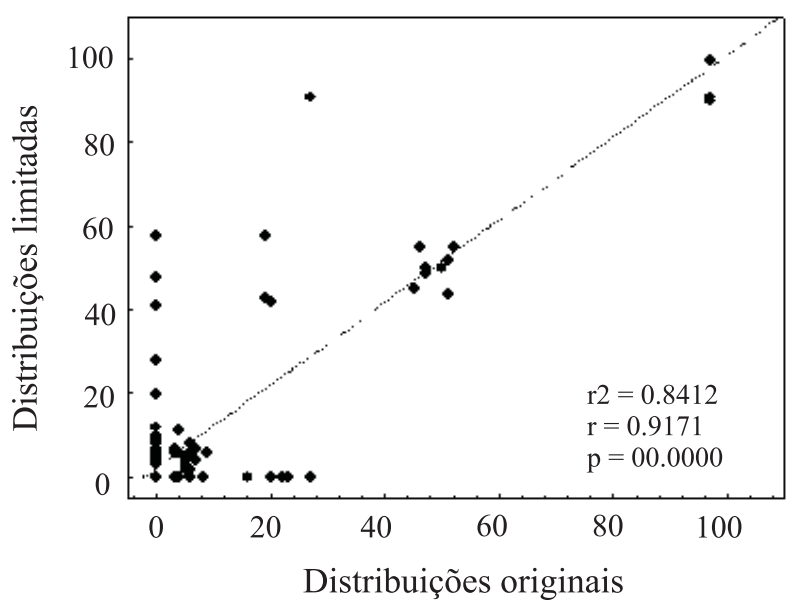

Fig. 7. Correlação entre os valores de insubstituibilidade obtidos a partir das soluções com os dados de distribuições originais espécies de anuros no Cerrado e os dados de distribuições sem as bordas.

uma delas tornam-se atraentes, embora haja dificuldades operacionais na identificação dessas populações. Modelos que assumem um balanço na dinâmica entre populações centrais e periféricas podem fornecer uma perspectiva inicial para solucionar esse problema. Além disso, é preciso considerar fatores externos à simples questão biogeográfica, principalmente aqueles ligados aos padrões espaciais de ocupação humana (BALMFORD et al., 2001, Diniz-Filho et al., 2006). Por exemplo, o algoritmo poderia selecionar células com grande número de populações centrais para as espécies, mas essa escolha pode se tornar menos indicada se essas células também possuírem uma elevada população humana (ou valores elevados para quaisquer outros indicadores de ocupação humana, em termos de agricultura, demografia, etc.) (BALMFORD et al., 2001).

Agradecimentos. Agradecemos o apoio financeiro do CNPq (bolsa de IC a GCCP) e CAPES (bolsa de mestrado a MPP). A base de dados e as análises de dados foram possibilitadas através de recursos do programa PRONEX "Áreas prioritárias para conservação da biodiversidade no Cerrado e em Goiás”, da SECTEC/ CNPq (23234156).

\section{REFERÊNCIAS BIBLIOGRÁFICAS}

Andelman, S. J.; Ball, I.; Davis, F. W. \& Stoms, D. M. 1999. SiTES v.1.0, An analytical toolbox for designing ecoregional conservation portfolios. Technical report, The Nature Conservancy. Disponível em: <http://www.biogeog.ucsb.edu/ projects/tnc/toolbox.html>. Acesso em 11.08.2004.

ARAúso, M. B. 2002. Biodiversity hotspots and zones of ecological transition. Conservation Biology 16:1662-1663.

Araújo, M. B. \& Williams, P. H. 1999. The bias of complementarity hotspots toward marginal populations. Conservation Biology 15:1710-1720

Balmford, A.; Moore, J. L.; Brooks, T.; Burgess, N.; Hansen, L. A.; Williams, P. \& RahbeK, C. 2001. Conservation conflicts across Africa. Science 291:2616-2619.

Balmford, A.; Bruner, A.; Cooper, P.; Costanza, R.; Farber, S.; Green, R. E.; Jenkins, M.; JefFeriss, P.; Jessamy, V.; Madden, J.; Munro, K.; Myers, N.; Naeem, S.; Paavola, J.; Rayment, M.; Rosendo, S.; Roughgarden, J.; Trumper, K. \& Turner, R. K. 2002. Economic reasons for conserving wild nature. Science 297:950-953.

Bini, L. M.; Diniz-Filho, J. A. F.; Pinto, M. P.; Silva, M. S. D.; Carvalho, P.; Rangel, T. F. L. V. B. \& Bastos, R. P. 2004. 
Estabilidade dos algoritmos de seleção de unidades de conservação em relação à diversidade beta de anfíbios anuros no Cerrado. In: Congresso Brasileiro de UnidAdes de Conservação. 4 , Curitiba, 2004. Anais... Fundação o Boticário de Proteção à Natureza, Rede Nacional Pró Unidades de Conservação, v.2, p.234-240.

Brooks, T. M.; Mittermeier, R. A.; Mittermeier, C. G.; Fonseca, G. A. B.; Rylands, A. B.; Konstant, W. R.; Flick, P.; Pilgrim, J.; Oldfield, S.; Magin, G. \& Hilton-Taylor, C. 2002. Habitat loss and extinction in the hotspots of biodiversity. Conservation Biology 16:909-923.

Cabeza, M. \& Mollanen, A. 2001. Design of reserve network and the persistence of biodiversity. Trends in Ecology and Evolution 16:242-248.

Diniz-Filho, J. A. F.; Bini, L. M.; Pinto, M. P.; Rangel, T. F. L. V. B.; Carvalho, P. \& Bastos, R. P. 2006. Anuran species richness, complementarity and conservation conflicts in Brazilian Cerrado. Acta Oecologica 29:9-15.

Diniz-Filho, J. A. F., Bini, L. M., Pinto, M. P., Rangel, T. F. L. V. B., Carvalho, P., Vieira, S. L. \& Bastos, R. P. 2007. Conservation biogeography of anurans in Brazilian Cerrado. Biodiversity Conservation 16:997-1008.

Diniz-Filho, J. A. F.; Bini, L. M.; Vieira, C. M.; Souza, M. C.; Bastos, R. P.; Brandão, D. \& Oliveira, L. G. 2004. Spatial patterns in species richness and priority áreas for conservation of anurans in the Cerrado region, Central Brazil. Amphibia-Reptilia 25:63-75.

Ferrier, S.; Pressey, R. L. \& Barrett, T. W. 2000. A new predictor of irreplaceability of areas for achieving a conservation goal, its application to real-world planning, and a research agenda for further refinement. Biological Conservation 93:303-325.

Gaston, K. J. \& Blackburn, T. M. 2000. Pattern and process in macroecology. London, Blackwell. p.99-112.

Gaston, K.; Rodrigues, A. S. L.; Rensburg, B. J.; KolefF, P. \& Chown, S. L. 2001. Complementary representation and zones of ecological transition. Ecology Letters 4:4-9.

Klink, C. A. \& Moreira, A. G. 2002. Past and current human occupation, and land use. In: Oliveira, P. S. \& Marques, R. J. The Cerrado of Brazil: Ecology and Natural History of a Neotropical Savanna. New York, Columbia University. p.69-88.

Kluth C, Bruelheide H. 2005. Central and peripheral Hornungia petraea populations: patterns and dynamics. Journal of Ecology 93(3):584-595.

Lanoo, M. 2005. Amphibian Declines: The Conservation
Status of United States Species. Berkeley, University of California. p.03-06.

Lawler, J. J.; White, D. \& Master, L. L. 2003 Integrating representation and vulnerability: two approaches for prioritizing areas for conservation. Ecological Applications 13(6): 1762-1772.

Lawton, J. H. 1993. Range, population, abundance and conservation. Trends in Ecology \& Evolution 8:409-413.

Margules, C. R.; Nicholls, A. O. \& Pressey, R. L. 1988. Selecting networks of reserves to maximize biological diversity. Biological Conservation 43:63-76.

Myers, N.; Mittermeier, R. A.; Mittermeier, C. G.; Fonseca, G. A. B. \& Kent, J. 2000. Biodiversity hotspots for conservation priorities. Nature 403:853-858.

Pressey, R. L.; Johnson, I. R. \& Wilson, P. D. 1994. Shades of irreplaceability: towards a measure of the contribution of sites to a reservation goal. Biodiversity and Conservation 3:242-262

Pressey, R. L.; Possingham, H. P. \& Day, J. R. 1997. Effectiveness of alternative heuristic algorithms for identifying indicative minimum requirements for conservation reserves. Biological Conservation 80:207-219.

Pressey, R. L.; Humphries, C. J.; Margules, C. R.; Vane-Wright, R. I. \& Williams, P. H. 1993. Beyond opportunism: key principles for systematic reserve selection. Trends in Ecology \& Evolution 8(4):124-128.

Primack, R. B. \& Rodrigues, E. 2001. Biologia da Conservação. Londrina, Midiograf. p.55-67.

SMith, T. B.; Kark, S.; Schneider, C. J.; Wayne, R. K. \& Moritz, C. 2001. Biodiversity hotspots and beyond: the need for preserving environmental transitions. Trends in Ecology \& Evolution 16:431.

Stuart, S. N.; Chanson, J. S.; Cox, N. A.; Young, B. E.; Rodrigues, A. S. L.; Fischman, D. L. \& Waller, R. W. 2004. Status and trends of amphibian declines and extinctions worldwide. Science 306:1783-1786.

Tsuji, N. \& Tsubaki, Y. 2005. Three new algorithms to calculate the irreplaceability index for presence/absence data. Biological Conservation 119:487-494.

Vitousek, P. M.; Mooney, H. A.; Lubchenco, J. \& Melillo, J. M. 1997. Human domination of Earth's ecosystems. Science 277:494-499.

Vucetich, J. A. \& Waite, T. A. 2003. Spatial patterns of demography and genetic processes across the species' range: Null hypotheses for landscape conservation genetics. Conservation Genetics 4(5):639-645. 